\title{
The Usefullness of Percutaneous Transarterial Embolization in Patients with Severe Multiple Traumas
}

\author{
Ingyu You,***, Cheonghwan Lim* \\ Department of Radiological Science, Hanseo University ${ }^{*}$, Department of Dignostic Radiology, Hallym University Hospital ${ }^{* *}$
}

\section{다발성 손상에 의한 중증외상환자의 경피적 동맥색전술의 유용성}

\author{
유인규,***, 임청환* \\ 한서대학교 방사선학과*, 한림대학교병원 영상의학과**
}

\begin{abstract}
The study was conducted in patients who had undergone angiography and arterial embolization after being diagnosed with arterial bleeding among those registered with severe trauma at the admission to the department of emergency due to accidents. In the study, comparison was done between the survived group and the nonsurvived group to investigate the usefulness and the optimal performance timing of angiography and embolization as the survival-affecting factors and treatment methods for patients. The study was performed as a retrospective analysis in 45 patients who had undergone angiography and arterial embolization among those categorized as severe trauma patients from the emergency department of $\mathrm{H}$ hospital located in Gyeonggi-do from July, 2006 until December, 2010. The Injury Severity Score (ISS), the Revised Trauma Score (RTS), the hematocrit were the main outcome measurements. Arterial embolization was technically successful in all cases, transcatheter arterial embolization of arterial bleeding is a useful procedure in lowering the mortality and complication in severe trauma patients. and RTS, ISS, Hematocrit were the predictable early mortality factors. So bad vital sign patients must be progressed rapidly.
\end{abstract}

Key Words : Embolization, RTS, ISS, Hematocrit, Glasgow coma scale

\section{요야}

사고로 인해 응급실을 내원한 중증외상환자로 등록된 환자 중 혈관조영술을 시행 받고, 동맥 출혈이 진단되어 동 맥색전술을 시행 받은 환자를 대상으로 생존군과 사망군을 비교하여 생존의 영향을 미치는 인자와 치료방법으로 혈 관조영술 및 색전술의 유용성과 적절한 시행 시점을 연구하였다. 2006년 7월부터 2010년 12월에 경기도에 위치한 $\mathrm{H}$ 병원 응급실에 중증외상환자로 분류된 환자 중 혈관조영술과 동맥색전술을 시행한 환자 45 명을 대상으로 하여 후 향적 분석을 실시하였다. 주요 지표로 ISS(Injury Severity Score)와 RTS(Revised Trauma Score), 적혈구 용적률 (Hematocrit)를 삼았다. 다발성 손상의 의한 중증외상환자의 경피적 동맥색전술은 모두 성공적으로 시술되었고, 환 자의 사망률과 합병증을 줄이는데 도움을 줄 수 있으며, RTS, ISS, Hematocrit, 쇼크 등이 사망률 조기 인자로써 예측이 가능하였으며 생체활력증후가 안 좋은 환자는 색전술 시행 시점을 가능한 빠르게 진행시켜야 한다.

중심단어: 중증외상환자, 동맥색전술, 혈관조영술, 적혈구 용적률, 글라스고우 혼수계수 


\section{I. 서론}

사회가 복잡해지고 경제가 발전하면서 교통사고, 재해사고, 산업 재해 등의 각종사고가 증가하고 있으 며, 이에 따라 다발성 손상에 의한 외상환자가 점차로 증가하고 있다. 그 결과로 발생하는 중증외상은 중요 한 사망원인중 하나가 되고 있다. 의학적인 측면에서 중증외상환자를 정의한다면 둔상(blunt trauma)이나 관 통상 같은 외상으로 인해 뇌, 폐, 심장, 간, 신장 등 인 체 내부 주요 장기의 손상 또는 광범위한 신체 부위에 손상이 있으면서 이로 인해 쇼크나 다발성 장기 기능 부전 등의 심각한 합병증을 동반한 환자를 말한다.

2009년에 우리나라 사망원인 대분류별 사망률 추이 에 의하면 신생물(암), 순환기 계통(심장, 뇌혈관)의 질 환에 이어 외적요인의 의한 사망(운수사고, 자살, 사고 사)순으로 나타나고 있다 ${ }^{[1]}$. 중증외상환자는 매년 12 만 5 천명이 발생하고, 1 만 1 천명이 사망하는데, 적절하고 신속한 치료에 의하여 살릴 수 있는 중증외상환자는 3 천5백 명에 달한다. 중증외상환자의 사망률은 1998년 $50 \%$ 에서 2007 년에는 $33 \%$ 로 개선이 되었으나, 미국과 일본의 $10 \sim 15 \%$ 에 비하면 2 배가 넘는 수치이다 ${ }^{[2]}$. 중증 외상환자의 특성은 다른 질환과는 다르며 빠른 시간 안에 적절한 치료를 받지 못 할 경우 사망 및 후유증으 로 인한 영구적 장애를 남길 가능성이 높다. 중증외상 환자의 사망률을 낮추기 위해서는 사고를 예방하는 것 이 가장 중요하지만 사고 발생 후에 신속하고 적절한 외상처치가 이루어지는 진료체계가 구축되어야 한다. 이러한 과제들을 성공적으로 수행하기 위해서는 유용 한 외상환자에 대한 중등도 평가가 이루어져야 한다 ${ }^{[3]}$.

중증외상환자의 주요한 사망원인으로는 초기의 대 량출혈, 지속적인 쇼크와 대량수혈로 인한 지연성 합 병증이 중요한 원인으로 알려져 있다 ${ }^{[4]}$. 중증외상환자 의 사망률을 높이는 출혈의 형태에는 정맥손상으로 인한 출혈과 골절 및 장기손상에 의한 동맥손상 출혈, 골수 내 출혈이 있을 수 있는데, 이중에서 동맥손상에 의한 출혈은 진단이 지연되면 다량의 출혈로 인한 생 체활력 징후가 불안정하며 사망률이 높아지는 아주 중요한 질환이다 ${ }^{[5]}$. 중증외상환자의 동맥 손상의 의한 출혈 시에는 영상의학과에서 시행하는 혈관조영술과
동맥색전술은 진단과 지혈 치료를 신속하게 하는데 가장 효과적인 방법들 가운데 하나로 여겨지고 있다. 즉 신속한 혈관조영술을 이용하여 출혈되는 동맥을 확인하고 출혈되는 동맥에 대해 선택적인 색전술이 이루어져 다른 동맥 등에 손상을 피하면서 지혈을 유 도할 수가 있다.

본 연구의 목적은 중앙응급의료센터에서 운용되고 있는 국가응급환자진료정보망을 통해 중증외상로 분류 된 다발성 손상의 의한 동맥출혈 환자 중 혈관조영술 을 시행 받고, 동맥 파열이 진단되어 동맥색전술을 시 행 받은 환자를 대상으로 생존군과 사망군을 비교하여 생존의 영향을 미치는 인자에 대하여 알아보고자 하며, 동맥촬영 및 색전술이 적절한 치료방법으로 유용성과 적절한 시행시점을 연구하여 궁극적으로 예방사망률을 낮추기 위한 자료를 제공하고자 하는 것이다.

\section{II. 연구 대상 및 방법}

\section{1. 연구대상}

2006년 7월부터 2010년 12월 까지 경기도 소재 H대 학교병원의 응급센터에서 다발성 손상의 의한 외상으 로 내원하여 중앙응급의료센터의 국가응급환자진료정 보망을 이용한 중증외상환자의 등록체계를 이용하여 중등도 분석에서 중증외상으로 등록되고 지속적인 출 혈이 진행되거나 의심이 되는 환자 중 혈관조영술을 시행 받고, 동맥파열이 확인 되어 혈관색전술을 시행 받은 45 명을 대상으로 생존군과 사망군으로 나누어 후 향적 분석을 하였다. 동맥의 출혈을 동반하였으나 혈 관조영술을 시행 받지 않은 환자나, 혈관조영술을 시 행하였으나 동맥색전술을 시행하지 않은 환자는 연구 대상에서 제외하였다.

\section{2. 중등도 분석방법}

중증외상을 분류하는 외상지수에는 생체 징후와 신 체 진찰 소견만으로 신속히 중등도를 판정하는 방법 과 각종 임상 검사 결과와 수술 및 시술 결과를 이용 하는 방법이 있다. 중증외상환자의 의식수준을 명백하 게 구분하기는 어렵다. 이러한 어려움을 없애고자 그 동안 많은 연구와 방법이 제시되었으나 1972년 
Teasdale과 Jennets에 의해 제안된 글라스고우 혼수계수 (Glasgow coma scale; GCS)가 많은 지지를 얻어 널리 사용되고 있다. GCS는 개안 반응(eye opening; E), 언어 반응(verbal response; $\mathrm{V}$ ), 그리고 운동 반응(motor response; M)의 세 가지 항목으로 되어 있으며 각 항목 의 해당 점수의 합(3 15점)이 총체적인 반응점수가 된 다. 이러한 GCS을 바탕으로 생체징후를 가지고 중등 도 평가를 하는 방법이 RTS이다. RTS는 Glasgow coma scale(GCS), 수축기 혈압(Systolic Blood Pressure; SBP), 분당 호흡수(Respiration Rate; RR)를 기초로 하여 산출 되며 생체 징후를 통한 중증도 판정, 적정 진료 평가, 예후 판정등에 사용되고 있으며 RTS가 높을수록 생 존율이 증가하는 것으로 알려져 있다. RTS는 다음과 같은 식으로 계산이 된다.

$\mathrm{RTS}=0.7326 \times \mathrm{SBP}(\mathrm{c})+0.2908 \times \mathrm{RR}(\mathrm{c})+0.9368 \times$ GCS(c) 식(1)

식(1)에 나타난 c 는 0 에서 4에 이르는 코드 값으로 (Table. 1)와 같이 환원이 되며 중증외상환자는 RTS 점수 7점 이하로 분류하고 있다.

Table 1. Revised trauma score

\begin{tabular}{cccc}
\hline GCS & SBP (mmHg) & $\operatorname{RR}(/ \mathrm{min})$ & Coded Value \\
\hline $13 \sim 15$ & $>89$ & $10 \sim 29$ & 4 \\
$9 \sim 12$ & $76 \sim 89$ & $>29$ & 3 \\
$6 \sim 8$ & $50 \sim 75$ & $6 \sim 9$ & 2 \\
$4 \sim 5$ & $1 \sim 49$ & $1 \sim 5$ & 1 \\
3 & 0 & 0 & 0 \\
\hline
\end{tabular}

신체를 6 개 부위로 나누어 각 신체의 손상별 중등 도를 점수화한 것이 AIS(Abbreviated Injury Scale)이고 6 부위 중 중등도가 심한 순서대로 나열하여 이중 중증 인 상위 3 부위의 AIS 점수를 선택하여 이 3 부위 AIS 점수의 제곱 합으로 계산되는 것이 ISS이다(식 2).

$\mathrm{ISS}=\operatorname{AIS}(1)^{2}+\operatorname{AIS}(2)^{2}+\operatorname{AIS}(3)^{2}$ 식(2)

해부학적 손상정도를 파악하여 중등도를 평가하는
ISS는 정확한 검사 소견 혹은 수술 후의 결과를 알아 야 산출되므로 응급 환자의 초기 중증도 판정에는 사 용되지 않으며, 생존율 혹은 예후를 판정하는데 많이 사용되고 있고, 특히 각 병원마다의 적정 진료 수준을 평가 하는데 이용되고 있다. 현재 중증외상 특성화센 터를 운용하는 기관에서는 중앙응급의료센터에서 배 포된 AIS 2005 UPDATE 2008 version에 따라 AIS코드 를 입력하고 있고 ISS의 중증환자 분류는 ISS 15 점 이 상으로 분류하고 있다.

\section{3. 연구 방법}

혈관색전술을 시행 받은 45 명을 대상으로 응급정보 조사지를 통하여 인구통계학적 지표(성별, 나이), 내원 일자, 내원사유(질병여부, 의도성여부, 손상기전), 교통 사고 손상당사자, 내원경로, 응급실 퇴실 시 상태 등 기본적인 사항에 대해 항목을 구성한다. 생리적인 지 표들로 구성된 RTS 와 해부학적 손상지표들로 구성된 ISS로 중등도를 분석하였고, 혈액학적 검사기준은 전 혈에서 대부분을 차지하고 있는 적혈구의 비율을 나 타내는 적혈구 용적률(Hematocrit)으로 응급실 내원 후 색전술 시행 후로 나누어 분석하였다. 응급실 내원 후 혈관조영술을 시행하기 전까지 전혈에서 혈장과 혈소 판을 제거한 농축 적혈구를 수혈 받은 양을 생존군과 사망군으로 나누어 분석을 하였다. 다발성 손상의 의 한 중증외상환자에게 시행된 동맥색전술이 큰 부작용 이 없이 성공적으로 진행되고 적절한 진단과 치료법 인지 평가한다. 출혈이 확인되고 색전술을 시행한 혈 관의 개수를 파악하여 손상된 혈관의 개수의 따른 사 망률과의 관계를 분석하고 응급실을 내원하여 혈관조 영술을 시행하기 전까지의 시간간격을 조사하여 사망 에 영향을 미치는 인자인지 분석하였다.

자료처리는 통계의 패키지 프로그램 SPSS version 12.0 을 이용하여 분석하였다. 다발성 손상의 의한 중증 외상환자들의 혈관조영술과 색전술을 시행 받은 생존 군과 사망군 두집단 간의 혈액학적 지수, 중등도 분석, 수혈양, 색전혈관 수의 따른 차이 등을 t-test를 이용하 여 비교하여 분석하였고 두 집단군 간의 손상기전, 장 기손상 여부, 시술 시간대에 따른 차이 등을 $\mathrm{x}^{2}$ 검증을 시행하여 비교하였다. P 값이 0.05 이하일 때 통계적으 로 유의한 차이가 있는 것으로 간주하였다. 


\section{III. 연구 결과}

\section{1. 인구통계학적 생존군과 사망군의 분석}

혈관조영술과 색전술을 시행 받은 대상 환자 45 명 중 생존군이 29 명 $(64.4 \%)$, 사망군이 16 명 $(35.6 \%)$ 이었 다. 평균 연령은 $52.07 \pm 20.1$ 세 이며 생존군의 평균 연 령은 $49.55 \pm 18.63$ 세 이며 사망군의 평균 연령은 $56.53 \pm$ 22.42세 이었다.

60 세 이상의 연령에서 전체 사망의 9 예(56.3\%)가 발생 상대적으로 다른 연령층보다 많이 발생하였다 (Table 2). 남녀의 비율은 생존군에서 남성은 19 명 $(65.5 \%)$ 이며 사망군에서는 9명 $(56.3 \%)$ 이었고 여성은 10 명(34.5\%)이며 사망군에서는 7명(43.7\%)이었다

Table 2. Frequency analysis of patient age unit : age, (\%)

\begin{tabular}{c|cccc}
\hline Age & $14-40$ & $41-60$ & $61-88$ & Total \\
\hline Survivors & $9(20.0)$ & $13(28.9)$ & $7(15.6)$ & $29(64.4)$ \\
\hline Nonsurvivors & $4(8.9)$ & $3(6.7)$ & $9(20.0)$ & $16(35.6)$ \\
\hline Total & $13(28.9)$ & $16(35.6)$ & $16(35.6)$ & $45(100)$ \\
\hline
\end{tabular}

연구대상 전체가 응급실 내원 후 응급처치가 이루 어진 경우 중환자실 입원 치료를 하였으며 사망군에 서 사망의 원인은 급성 출혈로 인한 hypovolemic shock 이 7 예(43.75\%), 패혈증이 4 예(25\%), 다발성장기부전이 5 예 $(31.25 \%)$ 가 있었다.

\section{2. 중등도 분석에 의한 생존군과 사망군의 분석}

생체징후를 통한 중증도 판정에 이용되는 RTS는 생존군에서 $7.57 \pm 0.67$ 점이며 사망군에서는 $6.08 \pm 2.01$ 점 이었다. 동맥색전술을 시행한 생존군과 사망군의 RTS 의 관계는 통계적으로 유의하게 나타났다 $(\mathrm{p}<0.05)$, (Table. 3).
Table 3. Characteristics of patient RTS

unit : point

\begin{tabular}{c|c|ccc}
\hline RTS & $\mathrm{N}$ & mean value & $\mathrm{t}$ & $\mathrm{p}$-value \\
\hline Survivors & 29 & $7.57 \pm 0.67$ & & \\
\hline Nonsurvivors & 16 & $6.08 \pm 2.01$ & -3.643 & 0.001 \\
\hline Total & 45 & $7.04 \pm 1.48$ & & \\
\hline
\end{tabular}

임상검사 결과와 수술 및 시술 결과를 이용하여 중 증도 분석을 하는 ISS는 생존군에서 23.62 \pm .27점이며 사망군에서는 $28.63 \pm 8.07$ 점이었다. 중증환자로 등록이 되는 ISS 15점 이상은 1명을 제외한 모든 대상에서 발 생하였고 ISS 30 점 이상에서는 환자 7 예에서 1 예를 제 외한 6 예에서 사망을 하였다. 동맥색전술을 시행한 생 존군과 사망군의 ISS의 관계는 통계적으로 유의하게 나타났다 $(\mathrm{p}<0.05)$, (Table. 4).

Table 4. Characteristics of patient ISS

unit : point

\begin{tabular}{c|c|ccc}
\hline ISS & $\mathrm{N}$ & mean value & $t$ & $\mathrm{p}$-value \\
\hline Patient & 29 & $23.62 \pm 4.27$ & & \\
\hline Survivors & 16 & $28.63 \pm 8.07$ & 2.731 & 0.009 \\
\hline Tonsurvivors & 45 & $25.40 \pm 6.30$ & & \\
\hline
\end{tabular}

\section{3. 혈액학적 분석에 의한 생존군과 사망군의 분석}

전체 혈액 중에 적혈구가 차지하는 비율을 표시한 적혈구 용적률은 출혈로 인한 전혈의 다량 손실에 따 른 전신 순환 혈액량의 부족을 평가하는 주요 평가항 목이다. 적혈구용적률는 생존군에서 $25.94 \pm 7.53 \%$ 이었 고 사망군에서는 $20.64 \pm 8.47 \%$ 이었다. 적혈구 용적률 의 분포를 보면 $30 \%$ 이상인 경우가 9 예 이었고 이중에 서 사망한 예는 2 예가 있었다. 그 외 대다수의 환자들 은 $30 \%$ 이하가 대부분이어서 다발성 손상의 의한 출혈 이 많았음을 알 수가 있었고 적혈구 용적률 $20 \%$ 이하 에서는 사망률이 급격이 증가함을 알 수가 있었다. 동 맥색전술을 시행한 생존군과 사망군의 적혈구 용적률 의 관계는 시행한 결과 통계적으로 유의하게 나타났 다 $(\mathrm{p}<0.05)$, (Table. 5). 
"Journal of the Korean Society of Radiology, Volume 6, Number 2"

Table 5. Characteristics of patient Hematocrit (Hct) unit: (\%)

\begin{tabular}{|c|c|c|c|c|}
\hline Patient & $\mathrm{N}$ & mean value & $t$ & p-value \\
\hline Survivors & 29 & $25.94 \pm 7.53$ & \multirow{3}{*}{-2.162} & \multirow{3}{*}{0.036} \\
\hline Nonsurvivors & 16 & $20.64 \pm 8.47$ & & \\
\hline Total & 45 & $24.06 \pm 8.19$ & & \\
\hline
\end{tabular}

과다한 출혈로 인해 순환계가 우리 몸의 주요기관 에 충분한 혈액을 공급할 수가 없어 혈액량을 회복하 기 위해 시행한 수혈의 양은 생존군에서 $235.5 \pm 143.5 \mathrm{cc}$ 이었고 사망군에서 $189.33 \pm 126.91 \mathrm{cc}$ 이었다. 과반수 이 상의 환자에게서 $160 \mathrm{cc}$ 이상의 혈액을 수혈을 받은 것 으로 나타났다.

\section{4. 색전술 시술 시간대분석에 의한 생존군과 사망 군의 분석}

다발성 손상의 의한 중증외상환자의 색전술 시술시 간대를 분석해 보면 정규시간에 색전술을 시행한 예 가 29명이 있었고 생존군이 19명(65.5\%)이며 사망군이 10 명 $(34.5 \%)$ 이었고 야간응급 상황에서 색전술을 시행 한 예가 16 명이었고 생존군이 10 명 $(62.5 \%)$ 이고 사망군 이 6명 $(37.5 \%)$ 이었다(Table. 6).

Table 6. Frequency analysis of procedure time

unit : person, (\%)

\begin{tabular}{c|ccc}
\hline Patient Time & Regular(day) & Emergency(night) & Total \\
\hline Survivors & $19(42.2)$ & 10(22.2) & 29(64.4) \\
\hline Nonsurvivors & $10(22.2)$ & $6(13.4)$ & $16(35.6)$ \\
\hline Total & $29(64.4)$ & $16(35.6)$ & $45(100)$ \\
\hline
\end{tabular}

\section{5. 장기 손상 분석에 의한 생존군과 사망군의 분석}

장기 손상여부에 따른 색전술을 분석해 보면 장기 손상의 따른 색전술을 시행한 예가 23명이었고 이중 생존군이 14 명 $(60.9 \%)$ 이었고 사망군이 9명 $(39.1 \%)$ 이었 다(Table. 7).
Table 7. Frequency analysis of organ injury unit : person, (\%)

\begin{tabular}{|c|c|c|c|}
\hline Patient Organ & Injury & Non injury & Total \\
\hline Survivors & $14(31.1)$ & $15(33.3)$ & $29(64.4)$ \\
\hline Nonsurvivors & $9(20)$ & $7(15.6)$ & $16(35.6)$ \\
\hline Total & $23(51.1)$ & २2(48.9) & $45(100)$ \\
\hline
\end{tabular}

장기 손상이 없는 중증외상환자의 색전술은 22 명이 고 생존군이 15 명(68.2\%), 사망군이 7 명 $(31.8 \%)$ 이었다. 손상된 장기를 보면 간이 7예, 비장이 5예, 신장이 2예, 복부 소화기관이 2예, 2 개 이상 장기손상이 된 경우가 6예가 있었다.

\section{6. 혈관 손상 개수 분석에 의한 생존군과 사망군의 분석}

다발성 손상의 의한 중증외상환자의 경우 손상 출 혈부위가 한정되어 있지 않고 여러 곳에서 발생할 수 가 있다. 혈관이 손상되어 색전술을 시행한 혈관의 개 수의 따라 빈도분석을 하였다. 생존군에서 1 개의 혈관 이 손상되어 색전술을 시행 받은 환자의 경우가 전체 에서 12 명 $(26.7 \%), 2$ 개의 혈관이 손상되어 색전술을 시 행 받은 환자의 경우가 전체에서 9 명 $(20 . \%)$ 이었다. 생 존군에서는 최대 7 개 혈관까지 색전술이 시행이 되었 다. 사망군에서는 1 개의 혈관이 손상되어 색전술을 시 행 받은 환자의 경우가 전체에서 7명(15.6\%)이었고 사 망 군에서는 최대 6 개 혈관까지 색전술이 시행이 되었 으며 전체적으로 사망군에서는 균등한 분포를 이루고 있다(Table. 8). 다발성 손상의 의한 중증외상환자의 혈 관이 손상되어 색전술을 시행한 혈관의 개수는 생존 군에서 $2.34 \pm 1.69$ 개이고 사망군에서는 $2.56 \pm 1.75$ 개 이 었다.

사고 후 응급실을 도착하여 혈관조영술을 시행하기 까지의 시간은 생존군에서 $556.28 \pm 550.82$ 분이 측정되 었고 사망 군에서는 $227.94 \pm 136.33$ 분으로 측정되어 생 존군 보다 짧게 측정되었다. 표준편차가 크게 차이가 나는 이유는 생체활력 징후가 안정되어 있거나 응급 센터에 각 과마다 환자 진료에 대한 치료지침이 다르 고 환자상황에 따른 치료의 성격이 다르기 때문이다. 
Table 8. Frequency analysis of embolization vessle

unit : number, (\%)

\begin{tabular}{|c|c|c|c|}
\hline Vessle Patient & Survivors & Nonsurvivors & Total \\
\hline 1 & $12(26.7)$ & $7(15.6)$ & 19(42.3) \\
\hline 2 & $9(20.0)$ & $2(4.4)$ & $11(24.4)$ \\
\hline 3 & $1(2.2)$ & $2(4.4)$ & $3(6.7)$ \\
\hline 4 & $3(6.7)$ & $2(4.4)$ & $5(11.1)$ \\
\hline 5 & $2(4.4)$ & $2(4.4)$ & $4(8.9)$ \\
\hline 6 & $1(2.2)$ & $1(2.2)$ & $2(4.4)$ \\
\hline 7 & $1(2.2)$ & 0 & $1(2.2)$ \\
\hline Total & $29(64.4)$ & $16(35.6)$ & $45(100)$ \\
\hline
\end{tabular}

\section{7. 수상기전에 따른 생존군과 사망군의 분석}

다발성 손상의 의해 색전술을 시행한 중증외상환자 의 수상기전을 보면 보행자 교통사고가 16 명, 운전자 교통사고가 6명, 오토바이 사고가 4명, 자전거 사고가 1 명, 추락사고가 13 명, 둔상이 4명, 기타(구타)가 1 명이 었다. 사망군은 보행자 교통사고에서 7 명, 추락사고 에 서 6명이 발생하여 대다수를 이루었고 그 외 운전자 교통사고 2 명, 오토바이 사고에서 1 명이 발생하였다 (Table. 9).

Table 9. Frequency analysis of injury mechanibm

unit : person, (\%)

\begin{tabular}{ccc}
\hline Injury mechanism & Survivors & Nonsurvivors \\
\hline Pedestrian & $9(20.0)$ & $7(15.6)$ \\
Driver & $4(8.9)$ & $2(4.4)$ \\
Motorcycle & $3(6.7)$ & $1(2.2)$ \\
Bicycle & $1(2.2)$ & $0(0)$ \\
Fall down & $7(15.6)$ & $6(13.3)$ \\
Blunt & $4(8.9)$ & $0(0)$ \\
Other & $1(2.2)$ & $0(0)$ \\
\hline
\end{tabular}

\section{$\mathrm{IV}$. 고 찰}

다발성 손상의 의해 색전술을 시행한 중증외상환자 의 경우 본 연구에 의하면 교통사고와 관련된 비율이 높은 것을 알 수가 있다. 또한 통계적으로 남녀 간의 유의성은 없었으나 대상 군의 남녀의 비가 남성의 비 율이 여성보다 높았다. 이는 외국의 자료를 보더라도 위험을 받아들이는 태도가 남성의 경우 공격적이고, 위험을 감수하려는 경향이 높기 때문에 발생률이 높 다는 것이다 ${ }^{[6]}$. 신체 각 부위에 따른 선행연구를 살펴 보면 골반골절의 경우 사망을 예측할 수 있는 변수의 관한 연구가 많은데 환자의 연령도 사망률로 예측할 수 있는 변수라고 하였다 ${ }^{[7]}$. 본 연구에서는 생존군과 사망군에서는 유의한 차이를 보이지 않았다. 손상 기 전에 따른 사망 예측 변수들에 관한 연구에서도 생존 의 유무를 분석한 결과 유의한 차이를 보이지 않았다.

중증외상환자의 중등도 도구는 지금까지 많이 개발 되었지만, 아직 절대적인 표준으로 삼을만한 것은 없 다. 현재 널리 쓰이고 있는 것으로는 생리적인 지표들 로 구성된 RTS와 해부학적인 손상지표들로 구성된 ISS가 있는데 이들 지표들은 생리적인 면과 해부학적 인 면 어느 한쪽으로 치우치는 단점을 가지고 있다 ${ }^{[8]}$. ISS를 측정하기 위해서는 영상의학 사진, 수술 결과 등을 참고로 하여야 하기 때문에 이를 수집하기 위한 시간의 소요가 많고 전문성을 가져야 한다. RTS의 경 우는 사람의 의해서 측정이 되기 때문에 평가자간 일 치도가 떨어진다는 단점이 있으며 기도유지나 호흡이 불안정한 외상환자에서는 GCS 점수의 측정이 불가능 한 상황이 발생할 수 있다는 것이다. 이러한 단점들이 있으나 현재 중앙응급의료센터의 표준응급 진료정보 로 생존 예측에 대한 진료 관련 표준정보로서 응급의 료기관의 평가의 이용되고 있다. 이러한 중등도에 따 른 결과를 제대로 평가하여야만 그 결과의 산물인 환 자의 치료평가가 이루어져 예방가능 사망률을 낮출 수가 있다. 색전술을 시행한 중증외상환자의 RTS에서 는 생존군과 사망군에서 유의한 차이를 보였는데, 이 러한 결과는 다른 원인에 의한 쇼크들과 마찬가지로 초기의 활력징후들이 놓쳐서는 안 되는 주요 인자임 을 확인해 주었으며, 타 연구에서도 RTS와 쇼크를 사 
망의 주요한 예측인자로서 강조하고 있다 ${ }^{[9]}$. 사망예측 변수로서 ISS는 여러 연구에서 사망과 관련된 인자로 서 보고되고 있다. 본 연구에서도 AIS 각각의 손상점 수를 보면 안면부, 사지, 외부를 제외하고는 사망과 관 련이 있는 것으로 나타났고, 생존군과 사망군에서 유 의한 차이를 보였다. 장기의 손상은 대동맥이나 심장 손상 등을 제외한 장기손상 그 자체가 사망과 관련이 있기 보다는 장기 손상을 입을 정도의 큰 외력이 작용 했음을 설명해 주는 것이라 보인다.

다발성 손상의 의한 중증외상환자의 경우 출혈이 사망을 야기할 수 있는 큰 문제이기 때문에 출혈로 인 해 영향을 받을 수 있는 혈액검사 결과에 따라 출혈로 인한 조영제의 혈관의 유출이 생존군과 사망군에서 유의하게 나타났다. 동맥색전술에 사용되는 색전물질 은 색전하고자 하는 위치, 손상된 혈관의 부위와 손상 종류의 따라 다르게 사용되지만, 색전물질은 거의 대 부분 Gelform 과 Coil를 혼합하여 사용을 하였다. 출혈 부위가 크고 출혈량이 많이 발생한 곳에서 Glue를 사 용하는 경우가 2명이었다. 혈관박리(Dissection)가 생긴 우측 대퇴동맥(Rt. superficial femoral artery)에 혈류의 흐름을 막지 않고 치료하기 위해 금속스텐트 시술이 색전술과 함께 이루어진 환자가 1 명이 있었다. 가능한 손상동맥에 초선택적 색전이 이루어졌으며 색전 후 조영술을 시행하여 출혈이 없는 것을 확인하였다.

외상의 혈관색전술의 대한 적응증에 관한 연구들이 발표되고 있지만 아직까지는 논란의 여지가 많다. 결 론적으로 현재까지 중증외상환자의 대한 혈관색전술 의 적응증에 대해서 정립된 바가 없어, 각 의료기관 별로 치료지침을 만들어 이용하고 있는 실정이다. 본 연구에서도 전산화단층촬영 영상에서 조영제의 혈관 으로 유출이 확인되고 수혈 및 수액요법에도 혈액학 적 수치가 변하지 않거나 반응하지 않는 지속적인 쇼 크 상태인 경우로 하였으나 지속되는 쇼크의 정의가 명확하지가 않아서 혈관색전술이 빠르게 시행되지 못 하는 경우가 있다. 골반골의 선행연구를 보면 혈액학 적으로 불안정한 골반골 골절 환자에서 개복술과 동 맥색전술을 시행하는데 있어 우선 어떻게 할 것인가 에 대해선, 이전에는 복강 내 출혈이 있을 경우 동맥 색전술 보다는 개복술을 먼저 시행해야 된다고 주장 하고 있으나 최근에는 일단 수액이나, 수혈을 통하여
혈액학적으로 안정화 시킨 후 동맥색전술을 시행해야 한다는 의견이 우세하다 ${ }^{[10]}$. 다발성 손상의 의한 중증 외상과 같이 출혈부위가 광범위 하여 개복술을 진행 하기 어려운 경우 장기의 출혈이 진행되고 있는 경우, 출혈부위를 명확하게 알기 힘들 경우 영상유도하에서 정확하게 출혈부위를 진단하고 정상부위에 손상을 주 지 않으면서 신속하게 치료를 할 수 있는 혈관조영술 과 색전술이 매우 유용하며 혈관의 유출이 증명된 환 자들 모두 성공적인 치료를 시행하였다. 색전술 후에 도 적혈구 용적률이 증가되지 않는 경우는 손상의 정 도가 크며 동맥에서 출혈을 저지하였다 하더러도 정 맥출혈이나 골절에서의 출혈은 계속될 수 있기 때문 이다.

본 연구의 제한점은 후향적 연구이며 일괄적인 치 료지침이 세워져 있지 않은 상태에서 색전술을 진행 하였기 때문에 치료방법에 있어서 환자들 간에 차이 가 있을 수 있고, 치료 방법 결정에 따라 혈관조영술 이 결정되어 결과에 영향을 미칠 가능성이 있으며, 사 고 발생 후 24 시간이 초과한 환자, 중독, 화상, 전기손 상, 질식, 익수, 동물에 의한 손상 및 이물에 의한 손 상, 응급센터 방문 후 여러 가지 이유로 추적관찰이 이루어지지 못한 환자는 연구대상에서 제외되었다.

\section{$\mathrm{V}$. 결 론}

중증외상으로 분류된 다발성 손상에 의한 동맥출혈 환자 중 혈관조영술을 시행 받고, 동맥 파열이 진단되 어 동맥색전술을 시행 받은 환자 45 명을 대상으로 생 존군과 사망군을 비교하여 생존의 영향을 미치는 인 자에 대하여 후향적 분석을 하였으며 다음과 같이 나 타났다.

첫째, 동맥색전술은 조영제로 인한 심각한 합병증 은 발생하지 않고 안전하게 시술되었다. 가능한 손상 동맥에 초선택적 색전이 이루어졌으며 대상 환자 모 두 추가적인 동맥출혈은 확인되지 않았다.

둘째, 동맥색전술을 시행 받은 대상 환자 45 명 중 생존군이 29명, 사망군이 19명 이었다. 평균 연령은 $52.07 \pm 20.1$ 세 이며 생존군의 평균 연령은 $49.55 \pm 18.63$ 세 이며 사망군의 평균 연령은 $56.53 \pm 22.42$ 세 이었다. 남녀의 비율은 생존군에서 남성은 19 명이며 사망 군에 
서는 9명 이었고 여성은 생존군에서 10 명이며 사망군 에서는 7 명 이었다.

셋째, 생체 징후를 통한 중증도 판정에 이용되는 RTS와 각종 임상 검사 결과와 수술 및 시술 결과를 이용하여 중증도 분석을 하는 ISS는 생존군과 사망군 에서 모두 통계적으로 유의하였다 $(\mathrm{p}<0.05)$.

넷째, 출혈로 인한 전혈의 다량 손실에 따른 전신 순환 혈액량의 부족을 평가하는 적혈구 용적률도 통 계적으로 유의하였다 $(\mathrm{p}<0.05)$.

응급실로 내원한 다발성 손상에 의한 중증외상환자 에게서 발생한 동맥출혈 시 혈관조영술과 색전술은 유용성이 있으며 응급실을 내원 시 생체활력 징후, 혈 액학적 수치가 낮거나 쇼크가 발생 시 시행시점을 빠 르게 진행시켜야 한다.

\section{Acknowledgements}

본 논문은 “2010년도 한서대학교 교내 연구비 지원" 에 의해 연구되었습니다.

\section{Reference}

[1] 통계청. 2009년 사망원인통계 결과. 통계청 인구동향과. 보도자료, 2010. http://kostat.go.kr, 2005.

[2] 주승용. 외상환자의 예방 가능한 사망률 감소를 위한 외상대응체계를 위한 전문가간담회. 국회보건복지위원회. 보도자료, 2010. http://www..naver.com/joo350 /128865110.

[3] 김경환, 김홍용. "다발성 외상 환자의 예후 예측을 위한 외상 지수들의 유용성. " 대한외과학회지, Vol. 54, No. 6, (부록): pp.943-50, 1998.

[4] 류춘옥, 이상권, 서경진 등. "경피경간 동맥색전술을 이용한 외상성 출혈의 치료. 대한 방사선 의학회지, ” Vol. 25 , No. 2: pp.184-193, 1989.

[5] 조용호, 이희상, 김현철 등. “경피경간 동맥색전술을 이용한 골반골절에 동반된 동맥출혈의 치료. " 대한방사선의학회지, Vol. 41, No. 5: pp.903-908, 1999.

[6] Tien HC tremblay LN, Rizoli SB, Gelberg J, et al. "Radiation exposur from dignostic imaging in severely trauma patients. " $\mathrm{J}$ Trauma. Vol. 62, No. 1, pp.151-156, 2007.

[7] Starr AJ, Griffin, DR, Reinert CM, et al. "Pelvic ring disruptions:prediction of associated injuries, transfusion requirement, pelvic arteriography, complications, and mortality. " J Orthop Trauma. Vol. 16, No. 8, pp.553-561. 2002.
[8] 이경원, 이정헌,서강석 등. "흥부외상환자에서 손상정도계수와 새손상정도계수의 비교분석. " 대한응급의학회지, Vol. 13, No. 2: pp.201-211, 2002.

[9] George CV, Konstantinos GT, Pantelis V, et al. "A prospective study on the safety and efficacy of angiographic embolization for pelvic and visceral injuries. ” J Trauma. Vol. 52, No. 2, pp.303-308. 2002.

[10] Hagiwara A, Sakaki S, Goto H, et al. "The role of interventional radiology in the management of blunt renal injury " : a practical protocol. J Trauma. Vol. 51, No. 3, pp.526-531. 2001. 